\title{
Dengue virus tetra-epitope peptide expressed in lettuce chloroplasts for potential use in dengue diagnosis
}

\author{
Franciele Roberta Maldaner • Francisco José Lima Aragão • \\ Flávia Barreto dos Santos • Octavio Luiz Franco • Monique da Rocha Queiroz Lima • \\ Renato de Oliveira Resende • Raquel Medeiros Vasques • Tatsuya Nagata
}

Received: 24 January 2013 /Revised: 4 April 2013 /Accepted: 8 April 2013 /Published online: 25 April 2013

(C) Springer-Verlag Berlin Heidelberg 2013

\begin{abstract}
Dengue virus causes about 100 million cases of dengue disease per year in the world. Laboratory diagnosis is done mainly by serological techniques, which in many cases use crude virus extracts that may cause cross-reactions to other flaviviruses. These undesirable cross-reactions can be reduced or eliminated by using recombinant proteins based on restricted epitopes. Aiming to decrease flaviviral cross-reactions and non-specific interactions in dengue serological assays, a plant expression system was chosen for recombinant antigen production as a reliable and inexpensive dengue diagnostic tool. In the present report, the lettuce plastid transformation system was applied to achieve efficient and stable tetra-epitope peptide antigen production,
\end{abstract}

Electronic supplementary material The online version of this article (doi:10.1007/s00253-013-4918-6) contains supplementary material, which is available to authorized users.

F. R. Maldaner $\cdot$ T. Nagata

Departamento de Patologia Molecular, Universidade de Brasília, 70910-900 Brasília, Federal District, Brazil

\section{F. J. L. Aragão ( $\square)$}

Embrapa Recursos Genéticos e Biotecnologia, PqEB W5 Norte,

70770-900 Brasília, Federal District, Brazil

e-mail: francisco.aragao@embrapa.br

F. B. dos Santos · M. da Rocha Queiroz Lima

Laboratório de Flavivirus, Instituto Oswaldo Cruz, 21040-360 Rio

de Janeiro, Rio de Janeiro, Brazil

O. L. Franco $\cdot$ R. M. Vasques

Pós-Graduação em Ciências Genômicas e Biotecnologia, Centro de Análises Proteomicas e Bioquímicas, Universidade Católica de Brasília, SGAN Quadra 916, Módulo B, Av. W5 Norte,

70790-160 Brasília, Federal District, Brazil

R. de Oliveira Resende $\cdot$ T. Nagata $(\triangle)$

Departamento de Biologia Celular, Universidade de Brasília,

70910-970 Brasília, Federal District, Brazil

e-mail: tatsuya@unb.br and its reactivity was evaluated. For this purpose, one putative epitope at positions 34 to 57 of E protein within the junction site of domains I and II of dengue virus (DENV) 1 to 4 serotypes linked by glycine linkers was expressed in lettuce chloroplasts. The potential immunoreactivity for the four DENV serotypes was evaluated using sera from patients of positive and negative dengue cases. Results indicated an overall sensitivity of $71.7 \%$ and specificity of $100 \%$. No cross-reactions with the sera of yellow feverpositive or healthy individuals vaccinated against yellow fever were observed. This novel approach may provide an alternative system for the large-scale production of dengue recombinant antigens useful for serodiagnosis.

Keywords Dengue virus · Tetra-epitope antigen · Transplastomic plant $\cdot$ Dengue diagnostic

\section{Introduction}

Dengue virus (DENV) is an enveloped positive-strand RNA virus in the genus Flavivirus, family Flaviviridae, which causes one of the most prevalent arthropod-borne human diseases worldwide. About 100 million cases of dengue disease are registered every year. The infection causes subclinical, mild dengue fever or can causes a more severe form as dengue hemorrhagic fever or dengue shock syndrome (WHO 2009).

DENV consists of four antigenically distinct serotypes, known as 1 to 4 . The incidence of each DENV serotype changes frequently. The genome sequence divergence among the four serotypes is greater than $30 \%$ (Beaumier et al. 2008; Kanagaraj et al. 2011). Currently, dengue diagnosis is mainly performed by serological tests such as IgM antibody capture (MAC)-ELISA, IgG-ELISA, and NS1 antigen capture ELISA (Lima Mda et al. 2010) and/or 
molecular techniques (conventional reverse-transcription (RT)-PCR and real time RT-PCR) (Fry et al. 2011). However, molecular techniques require more specialized equipment, the standardization of protocols, and welltrained handlers to perform the assay (Fry et al. 2011), which are more expensive and difficult to manage in developing countries where dengue is endemic. The most common protocols used are MAC-ELISA and IgG-ELISA, which detect DENV-specific IgM and IgG antibodies in patients' sera (Lima Mda et al. 2010), but these protocols require the DENV antigen, and, in many cases, the antigen is produced by live DENV injection into the brain of suckling mice. The use of crude extract of virus represents a potential risk to manipulators due to exposure to infectious viral preparations. In addition, the viral antigens produced by this process may cause cross-reaction with antibodies of other flaviviruses due to common epitopes present in virions (Anandarao et al. 2006; Cuzzubbo et al. 2001). One viable alternative method to produce an antigen that reduces crossreaction is the expression of recombinant viral proteins based on restricted epitopes, which is inexpensive and safer in bio-security terms (Anandarao et al. 2006; Kurane 2007).

Since dengue is endemic in Brazil, an efficient and inexpensive diagnostic kit that is easy to produce and handle is always requested. In this situation, a plant protein expression system presents an alternative and attractive tool for recombinant protein production, including antigens. Transgenic plants have been used as they can constitute a low-cost approach, and the recombinant protein produced may be used at low purity in some cases; furthermore, protein production is easy to scale up according to demand (Lossl and Waheed 2011). One domain from DENV envelope protein (domain III) has already been expressed in Nicotiana plants, with a fusion of hepatitis B core protein, and this showed good immunogenicity and potential use for DENV vaccine or diagnostic reagent (Kim et al. 2010; Martinez et al. 2010), demonstrating the viability of the plant system to express DENV antigens. These two studies used plant viral vector systems to produce the DENV antigen, while in the present work, the chloroplast transformation system was chosen.

Due to some characteristics of chloroplast DNA transformation (transplastomic), this system is more advantageous than plant nuclear genome transformation. Many therapeutic proteins have been expressed in transgenic plants via the nuclear genome (Lim et al. 2011). However, nuclear transformants often present a low expression level of recombinant protein because of gene silencing (RNA interference) ability in the plant host and integrations in inappropriate loci (Daniell et al. 2002; Lim et al. 2011). Chloroplast genetic engineering has almost all the advantages of a bioreactor, escaping from plant gene silencing, although posttranslational modification is not ideal for some proteins due to the prokaryotic nature of the chloroplast. The chloroplast expression system still possesses good ecological characterization since, in many cases, gene flow via pollen is not observed (Lossl and Waheed 2011). During the last decade, the plastid transformation system has been well established and optimized. Viral and bacterial antigens have been expressed in plastids, and the initial immunological studies showed promising results in animal models (Lossl and Waheed 2011).

Lettuce (Lactuca sativa L.) was chosen as the plant host, because it is a commercially important crop and can be cultivated in indoor hydroculture systems; furthermore, it has already shown high potential for expression of heterologous proteins in its chloroplasts. Recent reports showed the utilities of lettuce plastid expression systems producing therapeutic proteins (Lim et al. 2011), vaccines (DavoodiSemiromi et al. 2010; Lossl and Waheed 2011), and DENV VLPs (Kanagaraj et al. 2011). In the present report, we used the lettuce plastid transformation system, which showed itself to be an efficient protein expression system. With this system, tetra-epitope peptide for potential use as antigen in diagnostic assays was successfully produced. The reactivity of this antigen to patients' sera was also evaluated.

\section{Materials and methods}

\section{Recombinant peptide selection and design}

The same epitope region of the E protein gene on DENV 1 to 4 serotypes covering a portion of domains I and II at the 34-57 position (24 aa) from E protein (a junction site), which was deduced from the literature on epitope mapping (Beasley and Aaskov 2001; Falconar 1999; Roehrig et al. 1990), was selected for multiepitope protein expression (Fig. 1a). All putative epitope sequences were obtained aligning DENV 1 to 4 amino acid sequences (GenBank accession numbers: DENV 1-AF226685; DENV 2-AAA17499; DENV 3-AY679147; and DENV 4-NP_073286, respectively), which were conserved in most isolates worldwide in each serotype. The tetraepitope peptide (named cE-DI/IIp) was designed comprising four DENV epitopes (ordered as DENV-4, -3, -2, and -1 sequences) joined by penta-glycine linkers between epitopes $-4,-3$, and -2 , and linked directly between -2 and 1 for the extended tertiary structure in C-terminal region. The hexa-histidine tail (HisTag) was added at the C-terminal of the tetra-epitope as a reference tag (Figs. 1b and 2). The codon usage was optimized for lettuce chloroplasts to obtain better translation efficiency. For convenient purification of tetra-epitope peptide as chloroplast compartment, no addressing or exporting peptide was added onto the peptide. 
Fig. 1 Amino acid sequence analysis of flavivirus epitope (a) and tetra-epitope peptide (b, c). a Multiple alignment of epitope region of domains I/II junction site: DEN-1 to 4 , dengue virus serotypes 1 to 4 ; $J E V$, Japanese encephalitis virus; $W N V$, West Nile virus; $Y F V$, yellow fever virus $(17 D D$ $=$ vaccine strain in Brazil); SLEV, St. Louis encephalitis virus. b Amino acid sequence of tetra-epitope with glycine linker and hexa-histidine tail c Model of tetra-epitope peptide compiled by PyMOL 3D model a

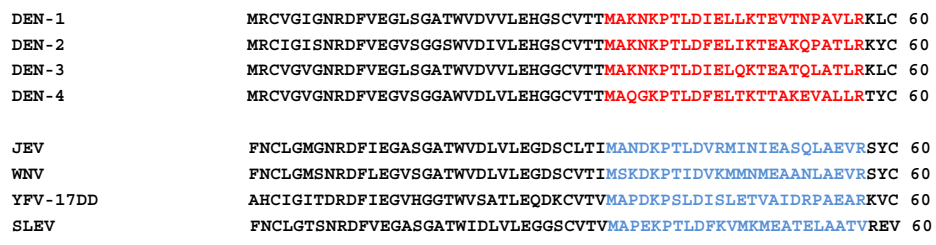

b

NH2 - MAQGKPTLDFELTKTTAKEVALLR-GGGGG-MAKNKPTLDIELQKTEATQLATLR-GGGGG- MAKNKPTLDFELIKTEAKQPATLR - MAKNKPTLDIELLKTEVTNPAVLRHHHHHH - $\mathrm{COOH}$

C

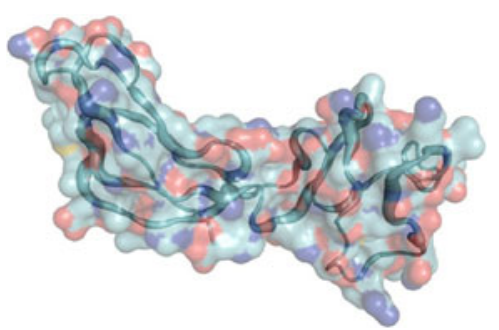

Protein structure prediction and epitope structural analysis

The Bioinfo Meta Server software (Ginalski et al. 2003) was initially used to indicate a specific template for the technique of threading. The best scores from the algorithm 3D Jury (J Score 35.75 and R-score 8.04) suggest the PDB structure (code 1oke) of crystal structure of the DENV-2 envelope protein (Modis et al. 2003) due to the high structural identity to the cE-DI/IIp peptide, which comprised amino acid residues from domains I/II.

Three hundred theoretical tridimensional peptide structures were constructed using Modeller v. 9.8 for each peptide (Sali and Blundell 1993; Eswar et al. 2006). The final peptide model, i.e., geometry, stereochemistry, and energy distributions in the model, was evaluated using PROSA II to analyze packing and solvent exposure characteristics and PROCHECK for additional analysis of stereochemical quality (Wiederstein and Sippl 2007) being DOPE and GA341 utilized for model selection. In addition, RMSD was calculated by overlap of $\mathrm{C} \alpha$ traces and backbones onto the template structure through the program 3DSS (Sumathi et

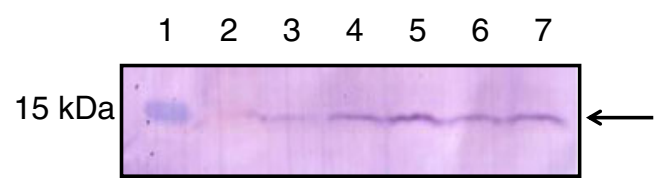

Fig. 2 Western blot analysis using anti-HisTag antibody. The arrow indicates the molecular mass of $14.8 \mathrm{kDa}$. Lane 1, benchmark prestained protein ladder (Invitrogen). Lane 2, crude extract from nontransformed lettuce plant. Lanes 3-7, crude extract from transformed lettuce leaves from $\mathrm{T} 1$ progeny al. 2006). The peptide structures were visualized and analyzed on Delano Scientific's PyMOL (DeLano 2002) (http:// pymol.sourceforge.net/). In order to calculate the grand average of hydropathicity, known as GRAVY, ProtParam was used, which is a tool that allows the analysis of various physical-chemical parameters for a given amino acid sequence (Wilkins et al. 1999).

\section{Lettuce plastid transformation}

The transformation vector used for lettuce chloroplast was based on the pRL1001, described by Kanamoto et al. (2006). The pRL1001 vector consists of the lettuce plastid $r b c L-a c c D$ intergenic region as a targeting site for homologous recombination, an aadA cassette (tobacco $r r n$ promoteraad $A$-tobacco $p s b A$ terminator) and a GFP expression cassette (tobacco $p s b A$ promoter- $g f p$-tobacco $r p s 16$ terminator). The $g f p$ was replaced by the DENV tetra-epitope gene cE-DI/II between the SphI and XbaI enzyme restriction sites to generate the vector pRL-DEN4-1, which was used for the transformation of lettuce (cv. Veronica) chloroplasts according to Kanamoto et al. (2006). Basically, lettuce plants were aseptically cultured on Murashige and Skoog (Wilkins et al. 1999) medium containing $3 \%(\mathrm{wt} / \mathrm{vol})$ sucrose and $0.6 \%(\mathrm{wt} / \mathrm{vol})$ agar under long-day conditions $(16 / 8 \mathrm{~h} \mathrm{light/dark})$ at $25^{\circ} \mathrm{C}$. For particle bombardment, young leaves of 3-4 week-old lettuces were harvested and used. Pieces of leaves were incubated for 1 day on regeneration media [Murashige and Skoog (MS) medium supplemented with $3 \%(\mathrm{wt} / \mathrm{vol})$ sucrose, $0.1 \mathrm{mg} / \mathrm{L}$ 6-benzylaminupurine (BAP), $0.1 \mathrm{mg} / \mathrm{L}$ alphanaphthaleneacetic acid, $0.6 \%$ agar (wt/vol), $\mathrm{pH} 5.8]$ with 
the adaxial side region directed upwards. The bombardment was conducted as previously described by Aragão et al. (1996). Bombarded leaves were kept for 2 days in the regeneration media, cut into pieces of $4 \mathrm{~mm} \times 4 \mathrm{~mm}$, and placed with the adaxial side down on the regeneration media containing $100 \mathrm{mg} / \mathrm{L}$ of spectinomycin and $500 \mathrm{mg} / \mathrm{L}$ polyvinylpyrrolidone. The backbone of $\mathrm{pRL}$ provides spectinomycin resistance for the transformed cells. Spectinomycin-resistant shoots were obtained 90 days after bombardment and were screened by PCR for the presence of the cE-DI/II gene, and, after confirming the positivity, a leaf piece of this shoot was subjected to three rounds of selection on spectinomycin selection medium to eliminate non-recombinant chloroplast DNA. Regenerating shoots were transferred into a sterile box containing the BAP phytohormone-free half-MS medium including $50 \mathrm{mg} / \mathrm{L}$ of spectinomycin for rooting. Plantlets were acclimatized and allowed to set seeds. Potential transplastomic plants were cultivated under long-day conditions $(16 / 8 \mathrm{~h}$ light/dark) in a greenhouse.

\section{Analyses of gene integration by PCR}

Chloroplast DNA was extracted according to Doyle and Doyle (1987), using CTAB buffer. Primers annealing the initiation site of the multiepitope gene (forward: 5'CTAGTGTGCTTGGGATC-3') and the coding regions of accD gene (reverse: 5'-CAATAGATGAATAGTCATT CGACG-3') were used for the confirmation of transgene integration. The amplified DNA fragments were analyzed by agarose gel electrophoresis.

\section{Chloroplast and tetra-epitope extraction}

Chloroplasts from $200 \mathrm{~g}$ of leaves were isolated by maceration in $8 \mathrm{~mL}$ of $1 \times \mathrm{PBS} \mathrm{pH} 7.4$ with $0.5 \mathrm{M}$ sucrose, filtered in cotton, and followed by two steps of centrifugation, one at $50 \times \mathrm{g}$ for $12 \mathrm{~min}$ separating supernatant, and the other at $1,000 \times g$ for $10 \mathrm{~min}$ to obtain a chloroplast pellet. For protein extraction, a pellet from $50 \mathrm{~mL}$ of filtered maceration was resuspended in $2 \mathrm{~mL}$ of $1 \times \mathrm{PBS} \mathrm{pH} 7.4$ with $1 \%$ Triton $\mathrm{X}$. After $15 \mathrm{~min}$ on ice, the clarification indicated the chloroplasts' lysis, and the light green supernatant was recovered for Western blot and ELISA assays. Then, the cE-DI/II epitope was purified using Ni-NTA purification system (Invitrogen) according to the manufacture's instruction.

\section{Western blot analysis}

Chloroplast proteins from $0.1 \mathrm{~g}$ of leaf was macerated with $100 \mu \mathrm{L}$ of PBS pH 7.2 containing $1 \%$ Triton X. After 15 min on ice, the lysate $(10 \mu \mathrm{L})$ were separated by $12 \%$ SDS-PAGE and transferred to a nitrocellulose membrane. The membrane was incubated in a blocking step with $4 \%$ skim milk in $1 \times$ PBS pH 7.2 for 30 min with agitation. After three washes ( 3 min each) with $1 \times$ PBS pH 7.2 containing $0.1 \%$ Tween 20 , the membrane was incubated with a commercially available murine anti-HisTag monoclonal antibody (1:5,000 dilution, Sigma-Aldrich) diluted in PBSskim milk for $60 \mathrm{~min}$. After three times of washing steps, the membrane was incubated with anti-mouse polyclonal IgG-alkaline phosphate conjugate $(1: 1,000$ dilution, Sigma-Aldrich) for $60 \mathrm{~min}$. The blotted membrane was washed three times and developed in NBT/BCIP substrate solution for $15 \mathrm{~min}$ at room temperature.

\section{In-house IgG-ELISA for detection of anti-DENV IgG} antibodies

In this study, the sera of 80 patients from DENV positive cases $(n=53)$ and non-dengue cases $(n=27)$ were analyzed in an in-house IgG-ELISA for detection of anti-DENV $\operatorname{IgG}$ antibodies using the DENV recombinant tetra-epitope protein produced in lettuce as antigen source. The tests included DENV-1 to 4 positive sera as well as positive DENV cases not serotyped from epidemics in the years 1998 to 2011. For the cross-reactivity and specificity studies, yellow feverpositive sera in convalescent phase and healthy individuals' sera with or without vaccinations against yellow fever were also analyzed. All sera were received at the Flavivirus Laboratory (Oswaldo Cruz Institute/Fiocruz, Brazil) as dengue fever suspect from patients with febrile illness consistent with dengue according to WHO criteria (WHO 2009). The DENV infection was further confirmed by virus isolation, detection of DENV RNA by RT-PCR, (Lanciotti et al. 1992) and/or detection by MAC-ELISA. The negative sera were considered as negatives by all the methods described above. Briefly, 96-well ELISA plates were washed five times with $200 \mu \mathrm{L}$ of $1 \times$ PBS pH7.4 containing $1 \%$ of Tween 20 (wash buffer). Each microwell was coated with $5 \mu \mathrm{g}$ of purified protein diluted in $60 \mu \mathrm{L}$ of PBS pH 7.4 buffer, for standers protocol, or with $60 \mu \mathrm{L}$ of cE-DI/II peptide crude extract diluted in carbonate/bicarbonate buffer $\mathrm{pH} 9.6$ or PBS pH 7.4 and incubated at $37{ }^{\circ} \mathrm{C}$ for $2 \mathrm{~h}$ or at $4{ }^{\circ} \mathrm{C}$ overnight. Then plates were washed five times with wash buffer and blocked in $10 \%$ normal goat serum in $1 \times$ PBS pH 7.4 (standard solution) for $1 \mathrm{~h}$ at $37{ }^{\circ} \mathrm{C}$. One hundred microliters of DENV positive or negative sera diluted in the standard solution were incubated at $37{ }^{\circ} \mathrm{C}$ for $45 \mathrm{~min}$ for IgG capture. After five washes (with wash buffer), $90 \mu \mathrm{L}$ of goat anti-human IgG peroxidase conjugate (Sigma-Aldrich) diluted 1:1,500 was added. After $45 \mathrm{~min}$ at $37^{\circ} \mathrm{C}$, the plates were washed five times again and $90 \mu \mathrm{L}$ of peroxidase substrate solution was added. Plates were incubated for 20-40 min at room temperature, and the optical density (OD) was measured at $405 \mathrm{~nm}$. Each serum sample was tested in duplicate. As a negative control, proteins 
isolated from non-transformed lettuce were used to coat the plates. The cutoff OD value for seropositivity was set above the mean OD plus three standard derivations of the negative control sera. The calculations of sensitivity, specificity, efficiency, negative, and positive predicted values were calculated as follows: sensitivity: TP/TP $+\mathrm{FN} \times 100 \%$; specificity: TN/TN + FP $\times 100 \%$; efficiency: TP + TN/TP $+\mathrm{FP}+\mathrm{FN}+\mathrm{TN}$, where TP is the number of true positive; FP, the number of false-positive; FN, the number of false negative; and $\mathrm{TN}$, the number of true negative.

\section{Accession number}

This tetra-epitope gene sequence was deposited in the EMBL/DDBJ/GenBank databases with the accession number of AB779692.

\section{Results}

Design of tetra-epitope DENV recombinant protein (cE-DI/IIp)

By the multiple alignment of amino acid sequences of envelope protein of four serotypes of DENV and other common flaviviruses [yellow fever virus (YFV), Japanese encephalitis virus (JEV), West Nile virus (WNV), and St. Louis encephalitis virus (SLEV)], the region chosen for epitope expression (Fig. 1a) was variable among these viruses except one conserved motif KP[TS][LI]D observed with them (Fig. 1a). The order of amino acid sequences of each epitope was DENV-4/DENV3/DENV2/DENV1 (Fig. 1b). The extended coil structures were predicted in $\mathrm{C}$ terminus (Fig. 1c), and all epitopes seemed to be exposed.

\section{Analyses of gene integration}

To confirm the gene integration for lettuce chloroplast DNA, PCR was performed using a forward primer which anneals the flanking region of the gene and a reverse primer which anneals the $a c c D$ coding region in chloroplast genome. As expected, the fragment of $866 \mathrm{bp}$ was observed only in transplastomic lettuce DNA (Fig. S1).

\section{Protein expression analysis}

To confirm the peptide expression, Western blot analysis was performed using anti-HisTag antibody to detect DENV tetra-peptide with hexa-histidine in the $\mathrm{C}$ terminus. A crude chloroplast extract of transformed lettuce leaves from T1 progeny from the second round selection was analyzed (Fig. 2). The Western blot analysis (Fig. 2) showed the expression of the target protein in an expected size of approximately $12.1 \mathrm{kDa}$.
In-house IgG-ELISA using recombinant DENV tetra-epitope peptide

Aiming to access the potential use of the recombinant DENV tetra-epitope peptide in dengue diagnosis, we standardized an in-house IgG-ELISA protocol using purified tetra-epitope (data not shown). After standardizing protocol, the crude lettuce chloroplast from the plants of the second round selection by spectinomycin was used for antigen coating ELISA. For coating onto ELISA plate, two different buffers, $1 \times$ PBS pH 7.4 (the same used in extraction without Triton $\mathrm{X}$ ) and a carbonate/bicarbonate buffer $\mathrm{pH} 9.6$ were compared. No significant differences were observed in either buffer system (data not shown), so for further study, only phosphate buffer was used for antigen coating. The minimum volume of lettuce extract to detect DENV IgG antibodies in DENV positive sera was determined as $40 \mu \mathrm{L}$ diluted in $1 \times$ PBS pH 7.4 or in a carbonate/bicarbonate buffer $\mathrm{pH}$ 9.6. There were no positive reactions in negative controls using crude extract of non-transformed lettuce with dengue positive and negative sera (Table 1). A total of 80 human sera (53 DENV cases and 27 negative cases) were used to evaluate the potential use of DENV tetra-epitope antigen. In this analysis, an overall sensitivity of $71.7 \%$ and specificity of $100 \%$ (Table 2 ) were obtained. The assay efficiency was 0.86 . Preliminary results observed in Table 2 and in Fig. 3 indicated the differences between serotype sensitivities. A higher sensitivity was observed in DENV-1 cases $(91.6 \%$ [11/12]), while sensitivities of $86.6 \%(13 / 15)$ and $75 \%(9 / 12)$ were observed for DENV-2 and DENV-3 cases, respectively. The lowest sensitivity was observed in DENV-4 cases (18.2\% [2/11], Table 2). All three dengue confirmed cases from non-identified infecting serotypes were positive by IgG-ELISA using the tetra-epitope recombinant peptide (group E) (Table 2, Fig. 3). The cutoff value was set at 0.136 and DENV-2 showed the highest OD values for some sera (Fig. 3). As expected, there were no crossreactions with yellow fever (group $\mathrm{G}$ ) or healthy individuals vaccinated against yellow fever (group $\mathrm{H}$ ) or false-positive (groups F-I).

\section{Discussion}

Nowadays, many rapid tests for dengue immunochromatographic diagnosis have been developed and have become commercially available. However, the ELISA format still presents advantages over other methods due to its ease in handling a large number of samples and its relatively high sensitivity in detection of dengue (Peeling et al. 2010). Aiming to develop an inexpensive serological diagnostic tool for dengue in an ELISA format, with good sensitivity and specificity and ease of large-scale kit production, the 
Table 1 ELISA IgG using chloroplast protein crude extract from transformed and nontransformed lettuce
${ }^{a}$ The same sample was tested from each extract in duplicate (absorbance 1 and 2). The number in parentheses indicated the sample number. PBS $1 \times$ signifies the use of phosphate buffer instead of serum incubation

\begin{tabular}{|c|c|c|c|c|}
\hline \multirow[t]{2}{*}{ Sample ${ }^{\mathrm{a}}$} & \multicolumn{2}{|c|}{ Transformed lettuce } & \multicolumn{2}{|c|}{ Non-transformed lettuce } \\
\hline & $\begin{array}{l}\text { Absorbance } \\
1\end{array}$ & $\begin{array}{l}\text { Absorbance } \\
2\end{array}$ & $\begin{array}{l}\text { Absorbance } \\
1\end{array}$ & $\begin{array}{l}\text { Absorbance } \\
2\end{array}$ \\
\hline DENV-1 (1) & 0.205 & 0.217 & 0.112 & 0.104 \\
\hline DENV-1 (2) & 0.291 & 0.317 & 0.106 & 0.104 \\
\hline DENV-1 (3) & 0.18 & 0.17 & 0.091 & 0.099 \\
\hline DENV- 2 (1) & 0.256 & 0.254 & 0.068 & 0.07 \\
\hline DENV-2 (2) & 0.48 & 0.482 & 0.055 & 0.061 \\
\hline DENV-2 (3) & 0.194 & 0.193 & 0.062 & 0.057 \\
\hline DENV-3 (1) & 0.249 & 0.248 & 0.102 & 0.105 \\
\hline DENV-3 (2) & 0.223 & 0.244 & 0.062 & 0.067 \\
\hline DENV-3 (3) & 0.475 & 0.472 & 0.055 & 0.061 \\
\hline Negative serum with dengue symptoms (1) & 0.116 & 0.116 & 0.111 & 0.098 \\
\hline Negative serum with dengue symptoms (2) & 0.125 & 0.126 & 0.114 & 0.106 \\
\hline Health serum (1) & 0.110 & 0.107 & 0.105 & 0.108 \\
\hline PBS $1 \times(1)$ & 0.088 & 0.089 & 0.084 & 0.042 \\
\hline PBS $1 \times(2)$ & 0.092 & 0.096 & 0.093 & 0.089 \\
\hline PBS $1 \times(3)$ & 0.043 & 0.045 & 0.069 & 0.091 \\
\hline
\end{tabular}

lettuce chloroplast protein expression system was chosen. Due to the compartmentalization of expressed protein in lettuce chloroplasts, two simple centrifugation steps, followed by chloroplast lyses in phosphate buffer containing $1 \%$ Triton $\mathrm{X}$, are enough for antigen preparation, since other proteins from chloroplast do not show any crossreactivity to human sera. We produced a tetra-epitope recombinant antigen which was able to detect IgG antibodies against the four DENV serotypes of DENV with an overall sensitivity of $71.7 \%$ and specificity of $100 \%$ without the need for heavy-duty purification steps, which can reduce the production costs of the diagnostic test. Many commercially available ELISA kits use attenuated virus or recombinant virus protein produced in Escherichia coli or other cell cultures as their antigen source, which need fine purification for diagnostic use (Batra et al. 2011; Cuzzubbo et al. 2001; dos Santos et al. 2004). Otherwise, human sera may crossreact to host proteins, resulting in false-positive.

The overall sensitivity and specificity observed in our analysis for the detection of anti-DENV IgG can be considered as satisfactory when compared to other commercial kits. According to Peeling et al (2010) in an Evaluation of Diagnostics series, two kits that use DENV 1-4 recombinant antigen for the detection of $\operatorname{IgM}$ and $\operatorname{IgG}$ showed overall sensitivities of 77.8 and $60.9 \%$ with specificities of 90.6 and $90 \%$, respectively.

Transplastomic lettuce production can be done by planting the seed in soil or in a hydroponic system in confined
Table 2 IgG-ELISA by using crude lettuce extract from DENV tetra-epitope peptide from $\mathrm{E}$ domains I/II for the diagnosis of dengue serotypes $1-4$

\footnotetext{
${ }^{\mathrm{a}} \mathrm{A}-\mathrm{E}$, groups of DENV positive sera classified (or not) by serotypes; F-I, groups of DENV negative sera
}

\begin{tabular}{lcc}
\hline Group $^{\text {a }}$ & \multicolumn{2}{l}{ No. of positive sera/total tested (\%) } \\
\cline { 2 - 3 } & Negative & Positive \\
\hline A (DENV-1 cases, $n=12)$ & $1 / 12(8.3)$ & $11 / 12(91.6)$ \\
B (DENV-2 cases, $n=15)$ & $2 / 15(13.3)$ & $13 / 15(86.6)$ \\
C (DENV-3 cases, $n=12)$ & $3 / 12(25.0)$ & $9 / 12(75.0)$ \\
D (DENV-4 cases, $n=11)$ & $9 / 11(81.8)$ & $2 / 11(18.2)$ \\
E (DENV cases, serotype not identified; $n=3)$ & $0 / 3$ & $3 / 3(100)$ \\
Total for groups A-E, $n=53$ & $15 / 53(28.3)$ & $38 / 53(71.7)$ \\
F (healthy individuals, $n=05)$ & $05 / 05(100)$ & $00 / 05$ \\
G (yellow fever cases, $n=03)$ & $03 / 03(100)$ & $00 / 03$ \\
H (healthy individuals vaccinated against yellow fever, $n=03)$ & $03 / 03(100)$ & $00 / 03$ \\
I (negative dengue cases presenting dengue fever symptoms, $n=16)$ & $16 / 16(100)$ & $00 / 16$ \\
Total for groups F-I, $n=27$ & $27 / 27(100)$ & $00 / 27$
\end{tabular}


Fig. 3 IgG antibody response to DENV tetra-epitope produced in lettuce chloroplasts determined by in-house IgGELISA. The $A$ group, positive DENV-1 cases; $B$ group, positive DENV-2 cases; $C$ group, positive DENV-3 cases; $D$ group, positive DENV4 cases; $E$ group, DENV cases, serotype not identified;

$F$ group, healthy individuals; $G$ group, yellow fever cases; $H$ group, healthy individuals vaccinated against yellow fever; $I$ group, negative dengue cases presenting dengue fever symptoms

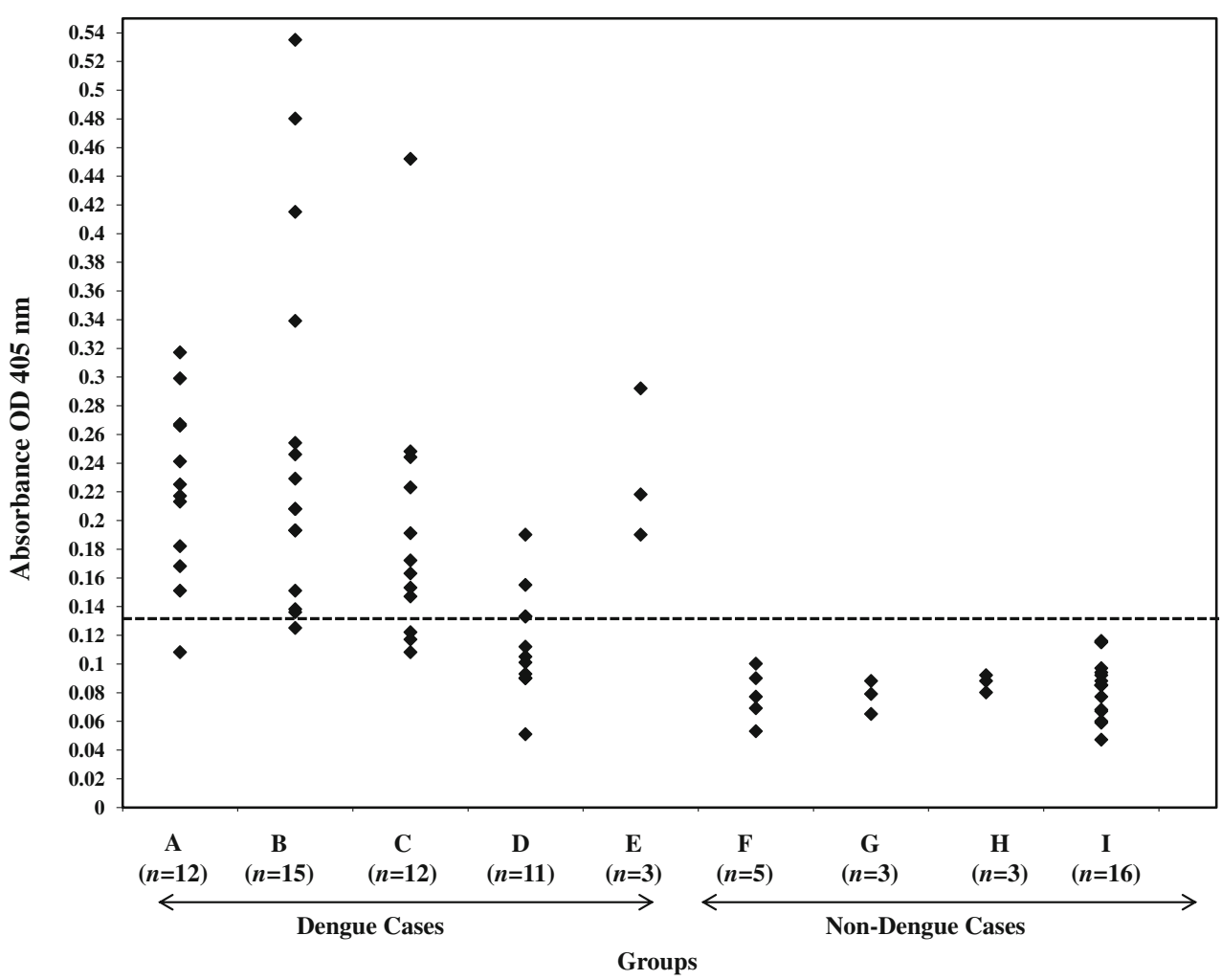

spaces and scaling up according to demand (Kanamoto et al. 2006), not requiring sophisticated infrastructure. The only laboratory equipment required for the production of the antigen is one middle-speed centrifuge for chloroplast precipitation, demonstrating the real potential of this system to produce DENV antigen inexpensively.

The epitope gene selected for four serotypes (which was the same position in E protein) is a rather unusual choice for DENV antigen. Most of the recombinant antigens for dengue detection targeting E protein use domain III (Batra et al. 2011; Martinez et al. 2010; Saejung et al. 2007), which is described as the most immunogenic epitope carrier of the envelope (Batra et al. 2011; Goncalvez et al. 2004; Gromowski and Barrett 2007; Lisova et al. 2007; Roehrig et al. 1998; van der Schaar et al. 2009). Our antigen covers the border region of epitopes of domains I and II of the four DENV serotypes. Despite already being described in the literature (Beasley and Aaskov 2001; Falconar 1999; Lai et al. 2007; Roehrig et al. 1990), these epitopes have not yet been used as a diagnostic tool. Lai et al. (2007) demonstrated the importance of epitopes located in domain I of DENV4 , since they neutralized viral infection by DENV-4 in vitro and conferred protection against infection with the same serotype in mice and Rhesus. In our study, the epitope position 34-57 aa showed good antigenicity, confirming the potential use of domains I and II as a diagnostic tool without cross-reaction with yellow fever, an endemic and important disease in Brazil (Table 2, Fig. 3). As observed in Fig. 1a, the amino acid analyses revealed significant divergences among DENV, STEV, YFV, JEV, and WNV except KP[TS][LI]D motif. Due to the absence of JEV and WNV and very low incidence of SLEV in Brazil (Mondini et al. 2007; Rodrigues et al. 2010), the cross-reactivity tests against these viruses have not been assessed yet.

Although the in silico model demonstrated that epitopes were exposed, in vivo conformation may assume different forms due to high structural flexibility. In this view, extended coil structures were predicted in $\mathrm{C}$ terminus (Fig. 1c). Despite the template shows a beta sheet conformation, a random coil conformation was observed here. This fact could be explained by the absence of non-covalent forces observed in the template complex structure that probably maintains such secondary structure. Moreover, the model analyses showed that most amino acids present in side chains would be exposed due to high flexibility of glycine linkers, giving this peptide theoretically exposed to the outside (Fig. 1c). This could be evaluated by high b-factors, represented by larger diameter ribbon structures, especially found in glycine-rich regions of threedimensional structural modeling (Fig. 1c).

However, serotype 4 might not be exposed enough to bind antibodies, which could explain the low efficiency of DENV-4 diagnostics compared to the other serotypes. The lower sensitivity of tetra-epitope for DENV-4 remained unclear.

Some commercial kits based on ELISA protocol, which were evaluated by Peeling et al. (2010), had a mean specificity of around 80-90\%, while the diagnostic system developed in this study showed the specificity of $100 \%$. This high specificity is probably due to the minimal cross- 
reactive proteins to human antibodies in lettuce crude proteins. This is a remarkable advantage against bacterial systems of recombinant protein expression.

Although our data are preliminary and the validation of the kit is still ongoing, the low-cost diagnostic tools developed in this study can contribute to all public and private health-care centers in Brazil, more precisely diagnosing dengue cases in this country.

Acknowledgments We thank Dr. Hirosuke Kanamoto (Research Institute of Innovative Technology for the Earth, Japan) for providing plasmid pRL1001. We also thank to Dr. Rita Maria Nogueira (Flavivirus Laboratory, IOC/Fiocruz, Brazil) for providing the samples. The work was funded by the Fundação de Apoio à Pesquisa do Distrito Federal (Brazil) for a research grant and by the "Conselho Nacional de Desenvolvimento Científico e Tecnológico" (CNPq, Brazil) for the DSc scholarship to the first author.

\section{References}

Anandarao R, Swaminathan S, Fernando S, Jana AM, Khanna N (2006) Recombinant multiepitope protein for early detection of dengue infections. Clin Vaccine Immunol 13:59-67

Aragão FJL, Brasileiro ACM, Ribeiro SG, Smith FD, Sanford JC, Faria JC, Rech EL (1996) Inheritance of foreign genes in transgenic bean (Phaseolus vulgaris) co-transformed via particle bombardment. Theor Appl Genet 93:142-150. doi:10.1007/ BF00225739

Batra G, Nemani SK, Tyagi P, Swaminathan S, Khanna N (2011) Evaluation of envelope domain III-based single chimeric tetravalent antigen and monovalent antigen mixtures for the detection of anti-dengue antibodies in human sera. BMC Infect Dis 11:64

Beasley DW, Aaskov JG (2001) Epitopes on the dengue 1 virus envelope protein recognized by neutralizing $\operatorname{IgM}$ monoclonal antibodies. Virology 279:447-458

Beaumier CM, Mathew A, Bashyam HS, Rothman AL (2008) Crossreactive memory $\mathrm{CD} 8(+) \mathrm{T}$ cells alter the immune response to heterologous secondary dengue virus infections in mice in a sequence-specific manner. J Infect Dis 197:608-617

Cuzzubbo AJ, Endy TP, Nisalak A, Kalayanarooj S, Vaughn DW, Ogata SA, Clements DE, Devine PL (2001) Use of recombinant envelope proteins for serological diagnosis of Dengue virus infection in an immunochromatographic assay. Clin Diagn Lab Immunol 8:1150-1155

Daniell H, Khan MS, Allison L (2002) Milestones in chloroplast genetic engineering: an environmentally friendly era in biotechnology. Trends Plant Sci 7:84-91

Davoodi-Semiromi A, Schreiber M, Nalapalli S, Verma D, Singh ND, Banks RK, Chakrabarti D, Daniell H (2010) Chloroplast-derived vaccine antigens confer dual immunity against cholera and malaria by oral or injectable delivery. Plant Biotechnol J 8:223-242

DeLano W (2002) The PyMOL molecular graphics system. Version $1.2 \mathrm{r} 3$ pre. LLC, Schrödinger

dos Santos FB, Miagostovich MP, Nogueira RM, Schatzmayr HG, Riley LW, Harris E (2004) Analysis of recombinant dengue virus polypeptides for dengue diagnosis and evaluation of the humoral immune response. AmJTrop Med Hyg 71:144-152

Doyle JJ, Doyle JL (1987) A rapid DNA isolation procedure for small quantities of fresh leaf tissue. Phytochem Bull 19:11-15

Eswar N, Webb B, Marti-Renom MA, Madhusudhan MS, Eramian D, Shen MY, Pieper U, Sali A (2006) Comparative protein structure modeling using Modeller. Curr Protoc Bioinformatics 15:5.6.15.6.30. doi:10.1002/0471250953.bi0506s 15

Falconar AK (1999) Identification of an epitope on the dengue virus membrane (M) protein defined by cross-protective monoclonal antibodies: design of an improved epitope sequence based on common determinants present in both envelope $(\mathrm{E}$ and $\mathrm{M})$ proteins. Arch Virol 144:2313-2330

Fry SR, Meyer M, Semple MG, Simmons CP, Sekaran SD, Huang JX, McElnea C, Huang CY, Valks A, Young PR, Cooper MA (2011) The diagnostic sensitivity of dengue rapid test assays is significantly enhanced by using a combined antigen and antibody testing approach. PLoS Negl Trop Dis 5:e1199. doi:10.1371/ journal.pntd.0001199PNTD-D-10-00128

Ginalski K, Elofsson A, Fischer D, Rychlewski L (2003) 3D-Jury: a simple approach to improve protein structure predictions. Bioinformatics 19:1015-1018

Goncalvez AP, Purcell RH, Lai CJ (2004) Epitope determinants of a chimpanzee Fab antibody that efficiently cross-neutralizes dengue type 1 and type 2 viruses map to inside and in close proximity to fusion loop of the dengue type 2 virus envelope glycoprotein. J Virol 78:12919-12928

Gromowski GD, Barrett AD (2007) Characterization of an antigenic site that contains a dominant, type-specific neutralization determinant on the envelope protein domain III (ED3) of dengue 2 virus. Virology 366:349-360

Kanagaraj AP, Verma D, Daniell H (2011) Expression of dengue-3 premembrane and envelope polyprotein in lettuce chloroplasts. Plant Mol Biol 76:323-333

Kanamoto H, Yamashita A, Asao H, Okumura S, Takase H, Hattori M, Yokota A, Tomizawa K (2006) Efficient and stable transformation of Lactuca sativa L. cv. Cisco (lettuce) plastids. Transgenic Res 15:205-217

Kim TG, Kim MY, Yang MS (2010) Cholera toxin B subunit-domain III of dengue virus envelope glycoprotein E fusion protein production in transgenic plants. Protein Expr Purif 74(2):236-241

Kurane I (2007) Dengue hemorrhagic fever with special emphasis on immunopathogenesis. Comp Immunol Microbiol 30:329-340

Lai CJ, Goncalvez AP, Men R, Wernly C, Donau O, Engle RE, Purcell RH (2007) Epitope determinants of a chimpanzee dengue virus type 4 (DENV-4)-neutralizing antibody and protection against DENV-4 challenge in mice and rhesus monkeys by passively transferred humanized antibody. J Virol 81:12766-12774

Lanciotti RS, Calisher CH, Gubler DJ, Chang GJ, Vorndam AV (1992) Rapid detection and typing of dengue viruses from clinical samples by using reverse transcriptase-polymerase chain reaction. J Clin Microbiol 30:545-551

Lim S, Ashida H, Watanabe R, Inai K, Kim YS, Mukougawa K, Fukuda H, Tomizawa K, Ushiyama K, Asao H, Tamoi M, Masutani H, Shigeoka S, Yodoi J, Yokota A (2011) Production of biologically active human thioredoxin 1 protein in lettuce chloroplasts. Plant Mol Biol 76:335-344

Lima Mda R, Nogueira RM, Schatzmayr HG, dos Santos FB (2010) Comparison of three commercially available dengue NS1 antigen capture assays for acute diagnosis of dengue in Brazil. PLoS Negl Trop Dis 4:e738

Lisova O, Hardy F, Petit V, Bedouelle H (2007) Mapping to completeness and transplantation of a group-specific, discontinuous, neutralizing epitope in the envelope protein of dengue virus. J Gen Virol 88:2387-2397

Lossl AG, Waheed MT (2011) Chloroplast-derived vaccines against human diseases: achievements, challenges and scopes. Plant Biotechnol J 9:527-539

Martinez CA, Topal E, Giulietti AM, Talou JR, Mason H (2010) Exploring different strategies to express Dengue virus envelope protein in a plant system. Biotechnol Lett 32:867-875

Modis Y, Ogata S, Clements D, Harrison SC (2003) A ligandbinding pocket in the dengue virus envelope glycoprotein. 
Proc Natl Acad Sci U S A 100:6986-6991. doi:10.1073/ pnas.08321931000832193100

Mondini A, Cardeal ILS, Lázaro E, Nunes SH, Moreira CC, Rahal P, Maia IL, Franco C, Góngora DVN, GóngoraRubio F, Cabrera EMS, Figueiredo LTM, Fonseca FG, Bronzoni RVM, Chiaravalloti-Neto F, Nogueira ML (2007) Saint Louis encephalitis virus, Brazil. Emerg Infect Dis 13:176178

Peeling RW, Artsob H, Pelegrino JL, Buchy P, Cardosa MJ, Devi S, Enria DA, Farrar J, Gubler DJ, Guzman MG, Halstead SB, Hunsperger E, Kliks S, Margolis HS, Nathanson CM, Nguyen VC, Rizzo N, Vazquez S, Yoksan S (2010) Evaluation of diagnostic tests: dengue. Nat Rev Microbiol 8:S30-S37. doi:10.1038/ nrmicro2459

Rodrigues S, Nunes MRT, Casseb SMM, Prazeres ASC, Rodrigues DSG, Silva MO, Cruz ACR, Tavares-Neto JCT, Vasconcelos PFC (2010) Molecular epidemiology of Saint Louis encephalitis virus in the Brazilian Amazon: genetic divergence and dispersal. J Gen Virol 91:2420-2427

Roehrig JT, Johnson AJ, Hunt AR, Bolin RA, Chu MC (1990) Antibodies to dengue 2 virus E-glycoprotein synthetic peptides identify antigenic conformation. Virology 177:668-675
Roehrig JT, Bolin RA, Kelly RG (1998) Monoclonal antibody mapping of the envelope glycoprotein of the dengue 2 virus, Jamaica. Virology 246:317-328

Saejung W, Fujiyama K, Takasaki T, Ito M, Hori K, Malasit P, Watanabe Y, Kurane I, Seki T (2007) Production of dengue 2 envelope domain III in plant using TMV-based vector system. Vaccine 25:6646-6654

Sali A, Blundell TL (1993) Comparative protein modeling by satisfaction of spatial restraints. J Mol Biol 234:779-815

Sumathi K, Ananthalakshmi P, Roshan MN, Sekar K (2006) 3dSS: 3D structural superposition. Nucleic Acids Res 34:W128-W132. doi:10.1093/nar/gk1036

van der Schaar HM, Wilschut JC, Smit JM (2009) Role of antibodies in controlling dengue virus infection. Immunobiology 214:613-629

WHO (2009) Fact sheet no 117, dengue and dengue haemorrhagic fever. World Health Organization, Geneva

Wiederstein M, Sippl MJ (2007) ProSA-web: interactive web service for the recognition of errors in three-dimensional structures of proteins. Nucleic Acids Res 35:W407-W410. doi:10.1093/nar/gkm290

Wilkins MR, Gasteiger E, Bairoch A, Sanchez JC, Williams KL, Appel RD, Hochstrasser DF (1999) Protein identification and analysis tools in the ExPASy server. Methods Mol Biol 112:531-552 